\title{
The Flowing Power in the Classroom and How Can Teachers Utilize Power Techniques to Improve Teaching
}

\author{
Jiale Song ${ }^{1}$ \\ ${ }^{I}$ College of Foreign Languages, Nanyang Normal University, Nanyang City, Henan Province, 473000, China \\ Corresponding author's e-mail: ShiLiShuang@cas-harbour.org
}

\begin{abstract}
In the documentary film Are our Children Tough Enough? Chinese School, the phenomenon of blocked power flow in the classroom was exposed. This paper focuses on the flow of power in the classroom and emphasizes Foucault's understanding of power relations. "Power is everywhere". "Power comes from everywhere" [1]. Power does not belong to individuals, but is constantly flowing in various roles of society. The same is true in the classroom., where the main bodies of power are teachers and students. This essay suggests that, in order to improve the effectiveness of classroom teaching, teachers should be fully conscious of the necessity of the flowing power in the classroom and take the initiative to utilize their roles to promote the cycle of power in the classroom. Teachers and students are supposed to share the power in the classroom so as to improve the effectiveness of classroom teaching. Drawing on Jennifer M. Gore' paper [2] and Catherine F. Brooks' findings in his research [3], this paper further analyzes the power techniques that teachers can utilize in the classroom. In Core' paper [2], she investigated eight major techniques of power (namely, surveillance, normalization, exclusion, classification, distribution, individualization, totalization, and regulation). In addition, Catherine F. Brooks examined how classroom roles reflect power relations in a course, how they are taken up, shift across time or are always in play and presented his findings [3]. By combining his findings with power techniques proposed by Core, this paper presents two suggestions for teachers. One is to choose an appropriate way of classroom interaction, using appropriate interaction to drive the flow of classroom power instead of mastering absolute power. Another is for teachers to reduce the use of advice-sounding directives, thus providing teachers and students with an equal position in the classroom dialogue in order to improve the experience of schooling for students and teachers.
\end{abstract}

Keywords: Power, power relations, power flow, power techniques

\section{INTRODUCTION}

The purpose of writing this paper is to analyze and explore the issue of power in the classrooms, based on a documentary produced by BBC. The documentary is called "Are our children Tough Enough, Chinese School", which records five Chinese teachers conducting a four-week Chinese-style experiment at a secondary school in Hampshire, southern England, aiming to compare the similarities and differences between Chinese and English teaching system. After the broad cast of this documentary, many scholars made in-depth analysis of Chinese and English teaching methods through diverse comparisons, which not only aroused wide attention and discussion in the education circle, but also promoted the integration of the two teaching modes to a certain extent. Regarding this documentary, from the experimental point of view, it indeed has certain loose loopholes, and there are also some inevitably objective factors. However, the issues exposed during the experiment are in urgent need of teachers' attention. The foremost problems are the facts that some Chinese teachers do not fully and accurately realize that power should be fluid in the teaching process. Michel Foucault, the French postmodernist, has been hugely influential in shaping understanding of power. "Power is everywhere" and "Power comes from everywhere" so in this sense is neither an agency nor a structure [9]. However, only a few studies have mentioned that high school teachers should make an account of the power flow in the classroom, proactively using the flowing power to enhance teaching efficiency. The paper emphasizes Foucault's theory of power. The starting point of this paper is to make more teachers realize the existent of power in the classroom and 
the importance of the constant flow of power during the teaching process. Recognizing that power in the classroom is dynamic and constantly flowing, then there are some questions worth analyzing. Can teachers actively promote the flow of power in the classroom in some ways? What power techniques can they utilize? How should they use these power skills to create more power flow cycles in the classroom so as to improve teaching? We construct in response to these questions will be informed by the theory of Michel Foucault and Jennifer M. Gore [2] and the findings of Catherine F. Brooks [3]. Therefore, the aim of this essay is to make more teachers comprehend the significance of power flow in classrooms and realize how to exercise power so as to turn it into a magic weapon for teaching.

\section{THE NEGATIVE EFFECTS AND CAUSES OF THE LACK OF POWER MOBILITY IN THE CLASSROOM}

The study [4] critically appraised the teacher-centered approaches of a Primary school in Kenya through experimentation. Findings of his study revealed that a teacher-centered approach has an adverse effect on student achievement. Teacher-led classrooms lead to cramming and rote learning that stifle students' imagination, creativity, and ultimately success. He suggested that teacher-centered teaching methods had permeated many primary schools and recommended that the government should come up with better policies. In a classroom completely dominated by teachers, students seem to be enslaved and passively learn knowledge under the tameness of teachers, which will give rise to unpleasant classroom experience and even severe mood of learning weariness. In fact, some teachers' behavior is actually potentially impeding the flow of power, which leads to the negative effects mentioned above.In the documentary, teachers who teach in the Chinese classroom adopt a very traditional Chinese method. Through a large number of blackboard writing, they directly present the concept in front of the students. They constantly use phrases like "listen to me" and "copy it all down" to reinforce their position in the classroom and ensure that they are the more powerful party. One primary problem with the Chinese classroom is that teachers lack the consciousness of changing roles in the classroom. They ignore the fluidity of power and excessively, taking themselves as the center, which leads to the boring class and decrease of students' enthusiasm. Meanwhile, many studies have also revealed that the flow of power in the classroom is often blocked and rarely valued by teachers. The project of Catherine F. Brooks [3] focuses on classroom talk as a way to see social role and power shifts embedded in the interaction between a teacher and students. He utilizes critical discourse analysis to examine the dynamic relationship between the power and roles of teachers and students in a face-to-face college course. He argues that role performance is laden with power relations and negotiations:

"Roles are socially constructed both locally (in specific situations that unfold relationally among a certain group of people) and culturally (developing within broader institutions and cultural communities). Roles develop relationally within local contexts, unfolding moment-to-moment in communication while being socially, culturally, and historically constrained by established societal structures. Classroom roles are thus a site for interrogating covert power (hegemony), overt power, control, resistance to normative or ritualized behavior, inclusion, or marginalization that happens as part of contemporary schooling." [3].

The roles of teachers and students in the classroom are partially influenced by traditional positions in society. In most classrooms there is an invisible hegemony that belongs to the teachers. The fundamental result of his research is to reveal the ritualized participation of teachers and students in the classroom, reflecting the absence of flowing power in the classroom. His five findings are that: the teacher as questioner in the face-toface environment; a teacher as a director; student as responders; using the role of responder to subvert the power structure; technology skill and student power [3]. This essay mainly focuses on the first three findings, which expose the teacher's neglect of effective role mobility in the classroom. The first finding is that teachers act as questioners in face-to-face teaching environments. In the discourse model of this typical classroom situation, the teacher, as the questioner, puts forward questions with specific known answers. And these known-information questions positioned teacher as the knower and situated the students as those without knowledge in the classroom [3]. There is no denying that this mode of interaction still exists in many classrooms today. In terms of such known-information question, if we compare the problem to a lock, then the teacher is the only person who holds the key in advance and has the absolute initiative. If students want to know whether their ideas are correct, they need to be evaluated by the teacher. In this situation mode, as the only judge, the teacher's authority is undoubtedly reinforced. As a result, it is difficult for students to hold power in the classroom, and the power flow in the classroom will be gradually frozen due to the interactive way proposed by teachers. The second finding is that the teacher exists as a director in face-to-face class. She often utilizes pronouns like "I" and "you" instead of "we" and "you", embedding these subtle cues in the expressions of her desires. She enjoys the role of director by offering advice-sounding directives. The roles of questioner and director are given to the teacher, but what about the power and role of the other main body in the classroom, the student? Not surprisingly, they become classroom responders. Students, as the largest group in the classroom, have only a slim chance of gaining power in such a ritualized, 
programmed, and instructed classroom. Only a small number of students can gain instant power by sharing their insights or raising doubts in the process of answering the teacher's questions. The whole teaching process does not contains too much power flow, which is not conducive to stimulate students' initiative in the learning process. The students only act as responders, cooperate with the teacher's ritualized teaching, and even accept their powerless status in the classroom. Therefore, the most worrying thing is not the harm of the lack of power mobility itself, but that many teachers as well as students have become accustomed to that conventional and unwise mode of classroom power flow, and do not realize that they are the key factors that lead to the freezing of classroom power flow.

\section{POWER, MODE OF POWER FLOW, POWER RELATIONS}

Foucault believes that power is decentralized and universal. "Power is everywhere" and "Comes from everywhere". So, in this sense, power is neither an agency nor a structure [9]. It permeates society, constantly changing and negotiating. In other words, power is decentralized. Central to Foucault's conceptualization of power is the idea that power exists in a network of micro powers rather than being located in a few individuals and organizations [5]. He argues that power is a kind of relationship, and it is not a simple relationship of topdown unidirectional control, but a complex "net-like" organization [5]. People usually regard the power relationship as unidirectional. The person in charge of power controls and dominates others from top to bottom, thus forming a linear relationship between the ruling and the governed. Foucault believed that power relations were not so simple, but interwoven networks. Everyone is in the interlacing power network and moves in the power network. In other words, in such a network, people may become the role of being controlled by the power as well as the role of implementing the power at the same time. Power should not be regarded as a privilege that certain people possess, but rather as a network of relationships working in perpetually tense activities.

Power in the classroom is also fluid. The subject of power in the classroom mainly includes teachers and students. And as Jesse Bazzul and Lyn Carter mentioned in the paper: "Examining relations of power can shed light on the relation between institutions, institutions and individuals, and between individuals (e.g., teacherstudent; student-student relationships)" [7].

The flow of power between students is mainly reflected in the process of group dialogue, teamwork and class management. In group conversations, for example, team members can take power by putting forward their own ideas, or they can retake the lead by contradicting other team members' ideas. In addition, power in the classroom flows mainly between teachers and students.
And the teacher's role is usually the more powerful one. In the cycle of power network, teachers are often the motive source of power flow since the beginning of the classroom means the beginning of power flow between teachers and students, and the starting mode of teaching is usually dominated by teachers through classroom design. Teachers can promote the flow of power through their words and deeds. Therefore,the relationship of power in the classroom and whether the power flows between teachers and students positively and effectively have a significant influence on teaching. Foucault highlights the importance of power relations in his book.

"Power relations are rooted deep in the social nexus, not reconstituted "above" society as a supplementary structure whose radical effacement one could perhaps dream of. In any case, to live in society is to live in such a way that action upon other actions is possible - and in fact ongoing. A society without power relations can only be an abstraction." [6].

Teachers must be fully conscious of the power relationship in the classroom, acknowledge that the power in the classroom should be shared by teachers and students, and recognize the subjectivity of students as power roles.

\section{TECHNIQUES OF EXERCISING POWER}

"If power is fluid, mobile, and exercised rather than owned, subsequent scholarly work ought address the means through which teachers and students perform as power "vehicles" [5] as the political and educational milieus continue to shift in educational institutions." [3]

Power can be seen as a tool. The question is, how should teachers effectively exercise power in the classroom?

In an empirical study Jennifer Gore (1995) has exploded the potential of Foucault's analysis of power for investigating pedagogical sites. She addresses two specific questions that contribute to the investigation of power relations in schooling: How is power exercised at the micro level of pedagogical practices? Are continuities evident in the functioning of power relations across different pedagogical sites? By studying four diverse sites, she distills eight power techniques, which are surveillance, normalization, exclusion, classification, distribution, individualization, totalization, and regulations [2]. Among the eight techniques, she highlights the importance of normalization.

"Educating is naming, communicating, and upholding norms - norms of behavior, of attitudes, of knowledge. Here, the productive exercise of power through normalizing techniques would seem to be a fundamental precept of pedagogical endeavor. That is, unless teachers can effectively exercise power to present and reinforce particular norms, teaching would not be a purposeful endeavor." [2] 
She believes that the exercise of some power in the teaching process to promote teaching is a basic norm. Furthermore, in [8], based on the power techniques put forward by Core, normalization and exclusion, they present instances of student-teacher interaction that foreground either Normalization or Exclusion, illustrate how them occurs in the studied classroom. Their study provides us with a more fine-grained understanding of how people operate by the embracing of certain teaching content. However, it remains to be explored and considered how teachers can effectively exercise power and turn it into a norm for daily classroom utilization.

According to the normalization, one of the eight power exercises proposed by Core, and in combination with the first two findings provided by [3], this essay will propose two teaching methods to help teachers promote the cycle of power flow in the classroom.

\subsection{The type of interaction}

Nowadays, many schools are emphasizing the interaction between teachers and students in the classroom. However, it is pointless for teachers to engage in ritualized interaction blindly, such as a series of questions with fixed answers. If the teacher always has an answer in mind before asking a question or has a plan before organizing an activity, it is difficult for the student to own power or plan in such an interaction. In this case, the flow of power in the classroom is frozen. Both teachers and students immerse in familiar classroom rituals, maintaining a kind of normalized hegemony. Who froze the flow of power in the classroom? Obviously, it is the teacher who has the power to set the form of classroom interaction. Hence, in order to allow the power flow in the classroom, the crucial factor is that the teacher should realize the importance of interactive forms and choose ones that are conducive to the students to hold part of the initiative. For example, a teacher may choose to ask questions that have no fixed answers. In this type of interaction, teachers can position themselves as a listener and judge rather than the sole authority. If they want to organize an activity, they can leave a certain blank space for the students to create freely instead of coming up with their own ideas or plans prepared in advance. The primary point is to be aware of the normalization of power [2]. Teachers are supposed to embed open-ended questions into conventional classroom interactions rather than those with fixed answers.

\subsection{Reducing the offering of advice-sounding directives}

Traditionally, teachers have been given an authoritative role rather than a facilitator role. Teachers who internalize the words "I" and "you" and "I think you should think this way" as routine unwittingly block the flow of power in the classroom. In order to realize the dynamic flow of power in the classroom and promote the efficiency of teaching, the two power subjects in the classroom, teachers and students should communicate and interact on an equal footing. However, teachers' first directive advice indirectly puts their expected way in front of students, which weakens students' power. Therefore, teachers should guide students to complete the teaching content together with themselves instead of arranging students' classroom power trajectory through direct or indirect instructions. In combination with normalization, that is to say, teachers can exercise their power to offer more non-imperative instructions, transforming the normal classroom routine into a norm for the joint participation of students and teachers.

\section{CONCLUSION}

Drawing on Foucault's conception of power relations, this paper shed light on the flowing power among teachers and students. As the subjects of power in the classroom, teachers and students always exist in the network of power. This paper attempts to reveal the phenomenon of the lack of flowing power in the classroom and calls for more teachers to change the traditional classroom norms and improve teaching efficiency through the exercise of power skills. Through the findings of F. Brooks' study (2016) [3], this essay further analysis and exemplify the blocked power flow between teachers and students in face-to-face classes. In addition, in order to answer the questions of what power techniques teachers can utilize and how to exercise them to improve the experience of schooling for students and teachers, this paper briefly introduces the eight power techniques Core proposed (1995) [2], with emphasis on the normalization. According to the findings in $\mathrm{F}$. Brooks' experiment, combined with the normalization Core proposed, this essay present two suggestions for teachers in terms of the type of interaction and the offer of directives. This paper suggests that teachers should change the usual way of interaction that will lock up the flow of power. On the contrary, teachers should design effective ways of classroom interaction to make equal and flowing power model a regular norm in the classroom. Moreover, this paper advocates that teachers should reduce the use of advice-sounding directives to help students better participate in the network of power flows. However, this paper only analyzes the power skills that teachers can exercise in the classroom according to the theory without giving in-depth examples through experiments. Although there have been scholars like her studying power relations in pedagogy, how to use power skills in the field and improve teaching quality still need to be further exemplified.

\section{REFERENCES}

[1] M. Foucault. Discipline and punish: The birth of the prison. New York: Random House LLC. 1977. 
[2] J.M. Gore. On the continuity of power relations in pedagogy. International Studies in Sociology of Education, 1995(5), pp. 165-188. Doi: 10.1080/0962021950050203.

[3] C.F. Brooks. Role, Power, Ritual, and Resistance: A Critical Discourse Analysis of College Classroom Talk, Western Journal of Communication, 2016, 80(3), pp. 348-369. Doi: 10.1080/10570314.2015.1098723

[4] C.S. Mackatiani. Learning Achievement: Illusions of Teacher-Centered Approaches in Primary Schools in Kenya. 2018.

[5] M. Foucault. Two lectures. In G. Gordon (Ed.), Power/knowledge: Selected interviews and other writings. New York: Pantheon Books. 1980, pp. 1972-1977

[6] M. Foucault. The subject and power. Critical inquiry, 1982(8), pp. 777-795. Doi:10.1086/448181.

[7] J. Bazzul, L. Carter. (Re) considering Foucault for science education research: considerations of truth, power and governance. Cult Stud of Sci Educ 12, 2017, 435-452. Doi: 10.1007/s11422-016-9800-2

[8] A.T. Danielsson, M. Berge, M. Lidar. Knowledge and power in the technology classroom: A framework for studying teachers and students in action. Cult Stud of Sci Educ 13, 2017, pp. 163-184

[9] M. Foucault. The history of sexuality: The Will to Knowledge, London, Penguin. 1998. 